\title{
Automatic Detection of Carbon Dioxide Concentration using IoT
}

\author{
Boby Siswanto, Johan M. Kerta, Ranny, Devwanto D. Nugroho
}

\begin{abstract}
Inside a classroom inhabited by students, carbon dioxide $\left(\mathrm{CO}_{2}\right)$ will be produced. Number of students and inhabiting time will affect the carbon dioxide concentration. This research implementing Internet of Things (IoT) devices to measure carbon dioxide level inside a classroom. Measurements taken are comparing carbon dioxide level of student activity between exam class and regular learning class. On 100 minutes of measurement found that carbon dioxide concentration inside exam class $5 \%$ higher than carbon dioxide concentration inside regular learning class with the same number of inhabitants.

Keywords : Carbon dioxide measurement, Internet of Things, Automatic Comparison, Classroom.
\end{abstract}

\section{INTRODUCTION}

Temperature and humidity are considered things to determine the comfort level of room [1]. Currently almost all rooms, including classrooms are equipped with Air Conditioners (AC). Temperature settings of the room can be controlled using the AC's remote. The humidity level is a variable that cannot directly controlled, it will be automatically adjusted to the specified temperature value compared to the heat value inside the room.

Classroom will be inhabited by a teacher and students. Teacher and students will breathe together inside the room and will produce carbon dioxide $\left(\mathrm{CO}_{2}\right)$. If the $\mathrm{CO}_{2}$ concentration inside the classroom reaches certain values, it can cause drowsiness or even adverse health effects [2]. The recommended $\mathrm{CO}_{2}$ value according to some previous studies is around $450 \mathrm{ppm}-1000 \mathrm{ppm}[3][4]$. Table- I shows the $\mathrm{CO}_{2}$ values and their categories based on the results of previous studies [5].

Table- I: $\mathrm{CO}_{2}$ Categories.

\begin{tabular}{ll}
\hline Categories & Values \\
\hline Normal Outdoor & $350-450 \mathrm{ppm}$ \\
Acceptable Level & $450-1000 \mathrm{ppm}$ \\
General Drowsiness & $1000-2500 \mathrm{ppm}$ \\
Adverse Health Effects & $2500-5000 \mathrm{ppm}$ \\
\hline
\end{tabular}

Previous research investigating carbon dioxide concentration at examination hall. Candidate of the exam

Revised Manuscript Received on April 25, 2020.

* Correspondence Author

Boby Siswanto*, Informatics, Bina Nusantara University, Bandung, Indonesia. Email: boby.siswanto@binus.ac.id

(C) The Authors. Published by Blue Eyes Intelligence Engineering and Sciences Publication (BEIESP). This is an open access article under the CC BY-NC-ND license (http://creativecommons.org/licenses/by-nc-nd/4.0/) should be wait at that hall for some time before entering the exam room. Carbon dioxide measured every 10 minutes. Found that carbon dioxide will be increased as the time period is increased [6]. Another research has done some implementation of controlling $\mathrm{CO}_{2}$ concentration inside a classroom to improve Indoor Air Quality by placing plants inside the classroom. Placing the plants inside a room able to reduce the carbon dioxide concentration [7].

Adjusting ventilation rates to control $\mathrm{CO}_{2}$ concentration inside a classroom also able to maintain the carbon dioxide level inside a classroom. It already done by other researcher [8]. This research will use IoT to measure the value of temperature, humidity and $\mathrm{CO} 2$ inside a classroom where all data will be recorded into a database. Internet of Things (IoT) is a technique that combines hardware, software, databases and computer networks to gain some purposes [9].

\section{OBJECTIVES}

This study aims to make a comparison of measurement of carbon dioxide concentration between exam class and regular lecture situation at the same classroom.

\section{RESEARCH METHODS}

Method of the research is done by designing tools using IoT microcontroller and sensors to obtain some data [10]. Microcontroller and sensors will be placed inside a classroom. Temperature, humidity and $\mathrm{CO}_{2}$ concentration will be obtained along with the current time and day values [11]. All of the IoT devices are connected to the internet via a Mikrotik router. Data will be recorder every 10 seconds on a database. Database will be installed at the web server located on the internet. There will be some software installed at the web server which are MySQL DB, PHP and Apache web server. All software operated on the Ubuntu Operating System. Temperature and humidity data will be obtained from DHT22 sensor and $\mathrm{CO}_{2}$ concentration data obtained from MHZ-19B sensor [12]. Analysis will be done by analysing obtained data of carbon dioxide against the 100 minutes of elapsed times. There will be two dataset to be compared which are dataset of regular lecture class and dataset of exam class. Both dataset will be compared on carbon dioxide concentration increments.

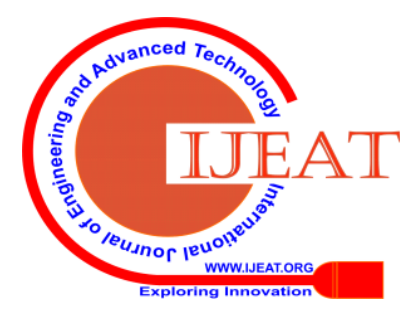




\section{Automatic Detection of Carbon Dioxide Concentration using IoT}

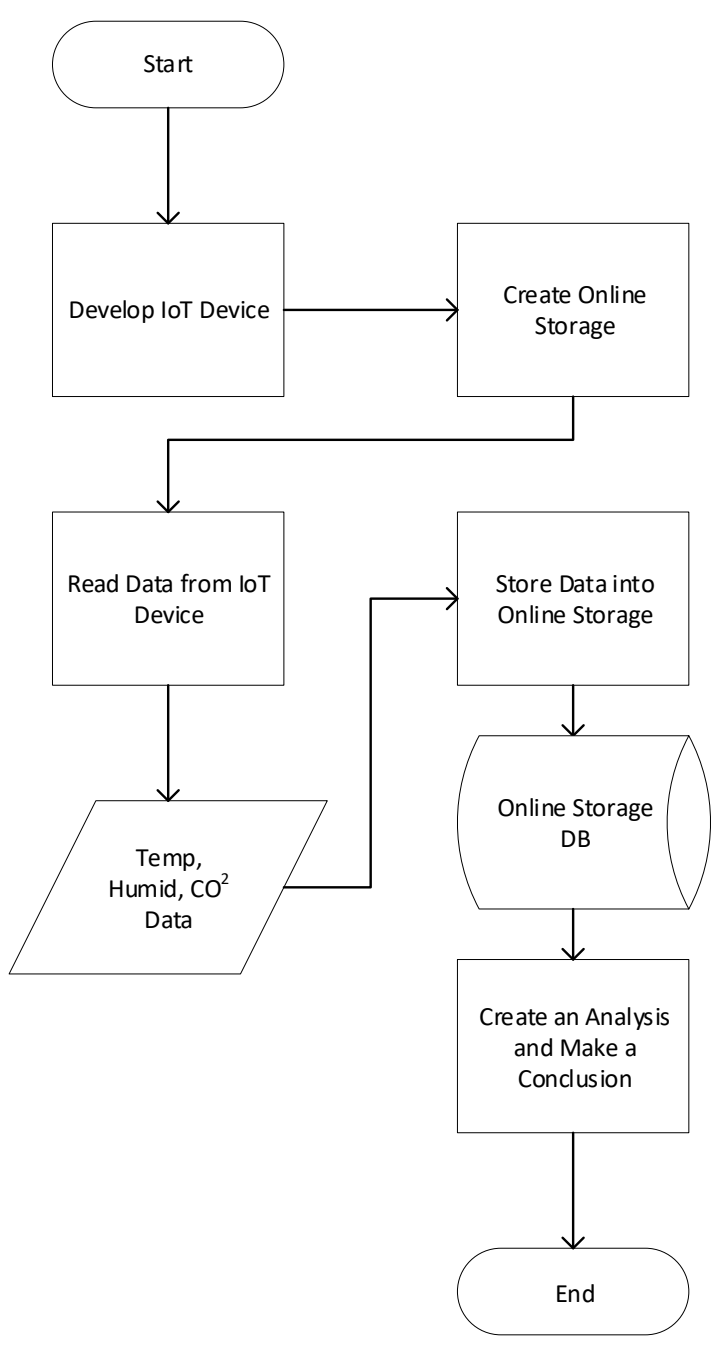

Fig. 1.Research Methods Flow Diagram

\section{IOT DESIGN}

Design will split into 2 parts, which are microcontroller program part and server program part. Parts of the microcontroller program located inside the classroom and the server program part located at the VPS (Virtual Private Server) webserver. Internet of Things devices list seen on Table- II. The IoT design illustration seen at the Figure 3.

Table- II: Internet of Things Devices List.

\begin{tabular}{ll}
\hline Name & Function \\
\hline NodeMCU ESP8266 & Micro Controller \\
DHT-22 & Temperature \& Humidity Sensor \\
GY-30 & Light illumination Sensor \\
MHZ-19B & Infrared CO2 Sensor \\
Mikrotik & WiFi Router \\
MySQL Database & Data Storage \\
VPS Webserver & (Ubuntu OS + Apache + PHP) \\
Putty & Interface to the VPS \\
\hline
\end{tabular}

The microcontroller program created using Arduino IDE, ESP8266 microcontroller will be used. Script of the Arduino program seen on Figure 3.

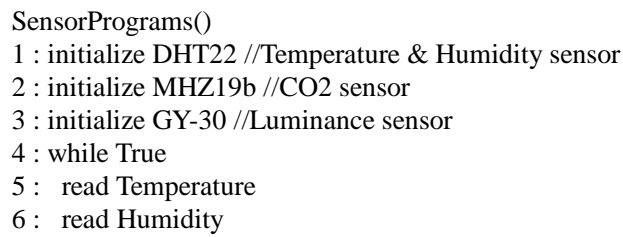

7 : read Luminance

8: read $\mathrm{CO} 2$

9 : sendToServer(Temperature, Humidity, Luminance, CO2)

Fig. 2. Arduini Microcontroller Program

Classroom usage is limited by a lecture session. Each session lasts for 100 minutes start from 7.20 until 17.00 (20 minutes break for each session transition).

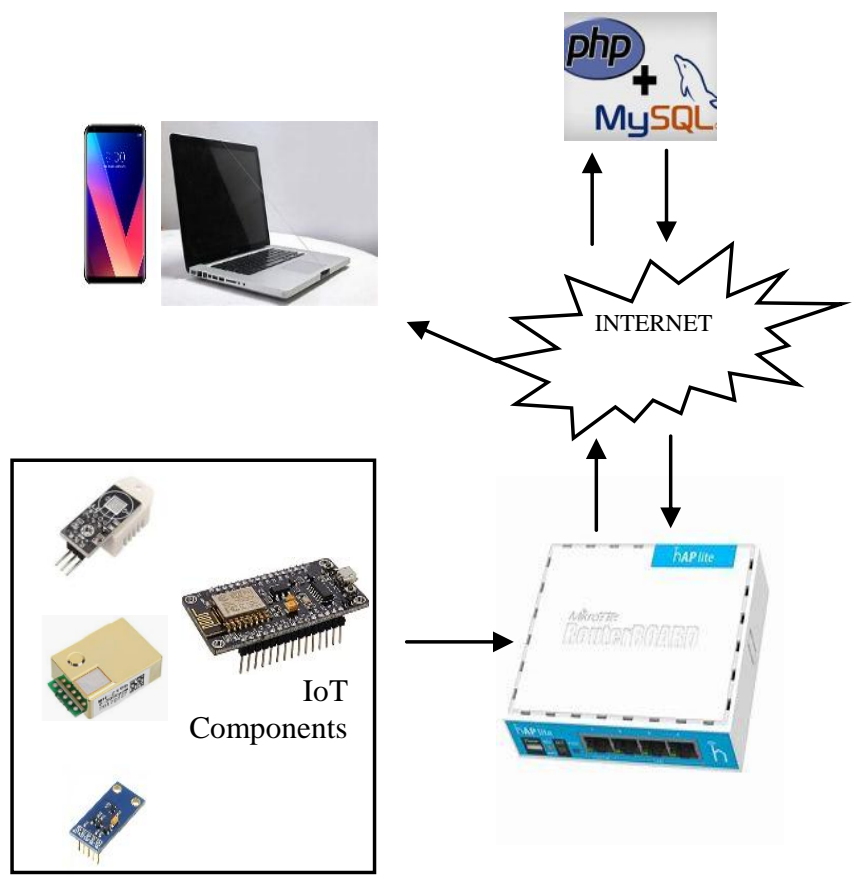

Fig. 3. IoT Microcontroller Program

\section{EXPERIMENTS AND DISCUSSIONS}

Classroom usage is limited by a lecture session. Each session lasts for 100 minutes start from 7.20 until 17.00 (20 minutes break for each session transition).

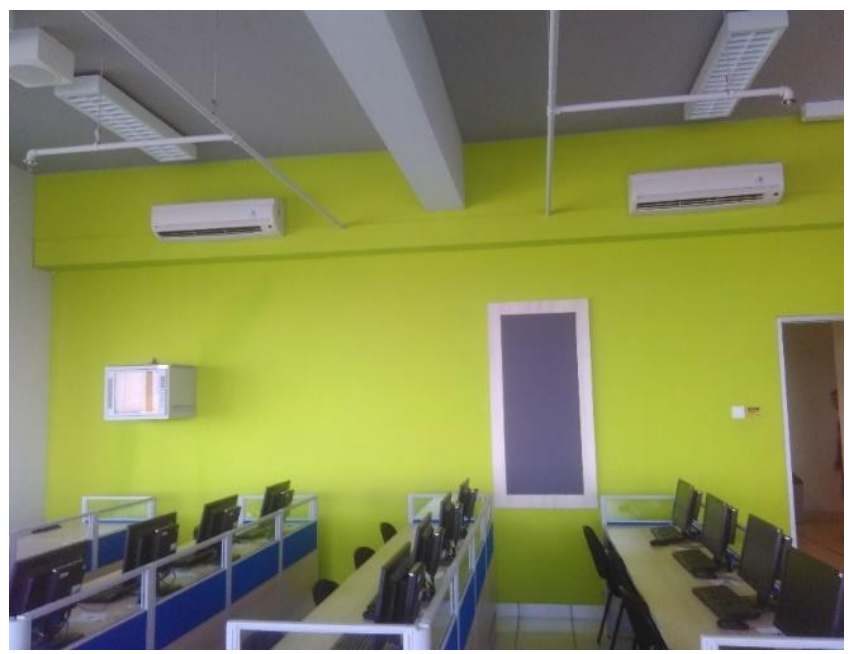

Fig. 4.Classroom Environment

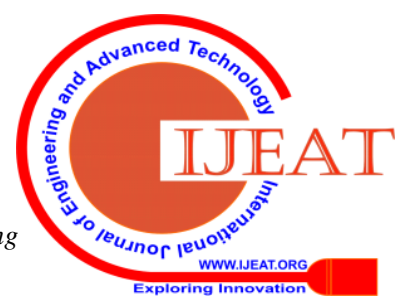


Table- III: Example of Data Obtained from IoT Sensors

\begin{tabular}{crrrr}
\hline \multicolumn{1}{c}{ Temo } & Humid & $\mathbf{C O}_{2}$ & Lux & Rdate \\
\hline 26.8 & 31.9 & 1245 & 312 & $11 / 11 / 201908: 59$ \\
26.8 & 31.9 & 1240 & 310 & $11 / 11 / 201908: 59$ \\
26.9 & 31.9 & 1230 & 311 & $11 / 11 / 201908: 59$ \\
26.9 & 31.8 & 1230 & 311 & $11 / 11 / 201908: 58$ \\
26.9 & 31.9 & 1220 & 311 & $11 / 11 / 201908: 58$ \\
\hline
\end{tabular}

This research is done by obtain data from 2 lecture sessions at 9.20-11.00 at the same classroom. First session is at regular lecture class and the second one is at the exam class. Example of obtained data at the database is shown at Table- III.

Experiments is done by comparing the two obtained dataset based on the student activity inside the classroom (general lecture and exam). Carbon dioxide concentration in the classroom is produced by the many occupants of the room and their activities.

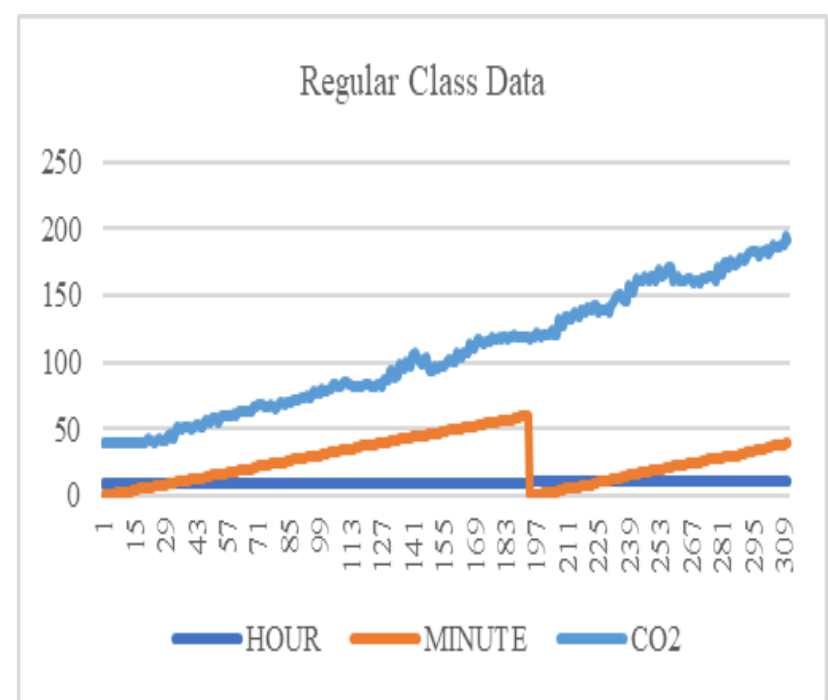

Fig. 5. $\mathrm{CO}_{2}$ concentration graph at regular class

Obtained data drawn into two graph. Figure 5 shows obtained regular learning class data and figure 6 shows obtained exam class data. Both data have same duration of time which is 100 minutes.

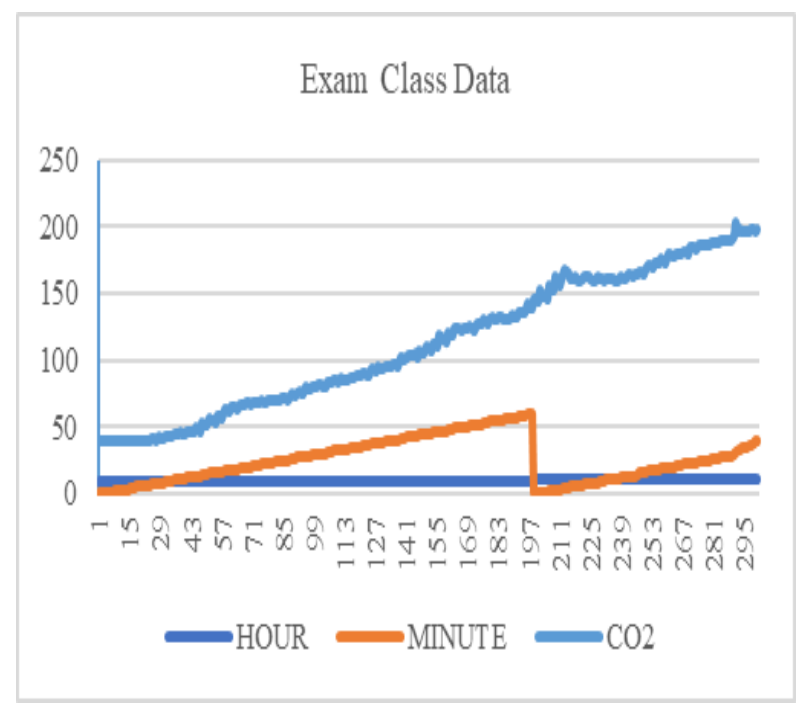

Fig. 6. $\mathrm{CO}_{2}$ concentration graph at exam class
Based on both graphs, found that exam class dataset has higher values on carbon dioxide concentration value than regular learning class dataset, shown on Table- IV.

Table- IV: Data Obtained Comparison

\begin{tabular}{rrrr} 
No & \multicolumn{1}{c}{ Minutes } & \multicolumn{1}{c}{ Regular } & \multicolumn{1}{c}{ Exam } \\
\hline 1 & 10 & 50,5 & 45,5 \\
2 & 30 & 76,5 & 79,5 \\
3 & 60 & 118,5 & 139,5 \\
4 & 90 & 171,5 & 189 \\
5 & 100 & 191,5 & 197,5 \\
\hline
\end{tabular}

Based on comparison graph on figure 7 , found that carbon dioxide concentration on exam class has higher value than the regular learning class after 30 minutes of elapsed time.

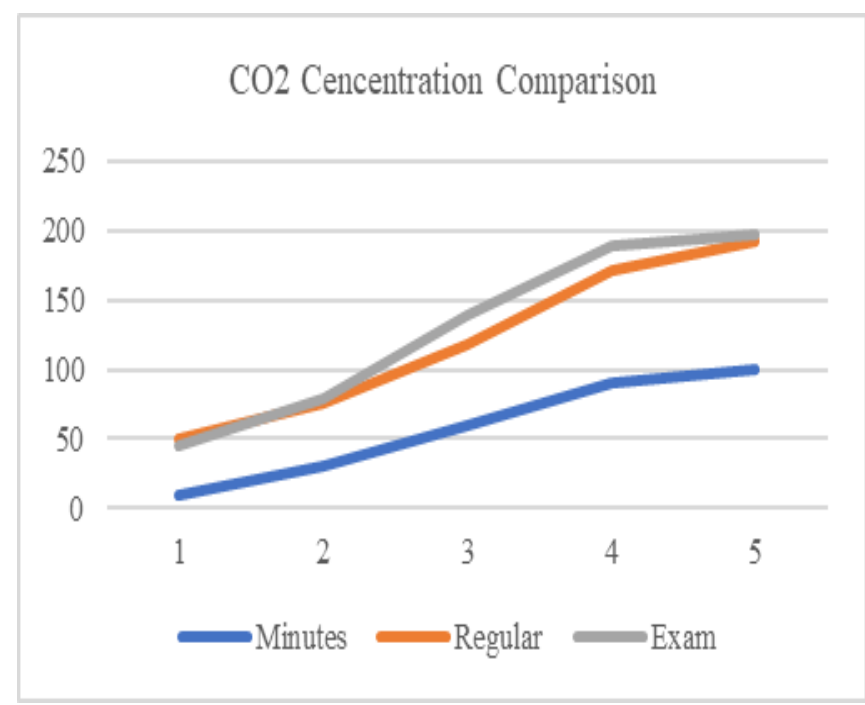

Fig. 7.Comparison graph between regular learning class and exam class

\section{CONCLUSION}

Based on the results on table- IV and comparison graph on figure 7 , the conclusion is carbon dioxide concentration on exam situation in higher than the regular class situation. The differences found after 30 minutes of elapsed time. It has 5\% higher on the average value. It indicates that inhabitants or students that resides inside the classroom will breath much heavier due to the exam pressure.

\section{REFERENCES}

1. M. R. Salim, H. M. Ibrahim, I. A. Azmi and M. Y. M. Noor, "Measurement of Carbon Dioxide Using Low-Cost \& Compact Spectroscopy Based Gas Sensor," Journal of Telecommunication, Electronic and Computer Engineering, pp. 127-132, 2018.

2. 2016J. Vanus, O. M. Gorjani and P. Bilik, "Novel Proposal for Prediction of CO2 Course and Occupancy Recognition in Intelligent Buildings within IoT," Energies, pp. 1-25, 2019.

3. J. Yang, H. Pan, W. Zhou and R. Huang, "Evaluation of smart classroom from the perspective of infusing technology into pedagogy," Smart Learning Environments, pp. 1-11, 2018.

Published By:

Blue Eyes Intelligence Engineering

\& Sciences Publication

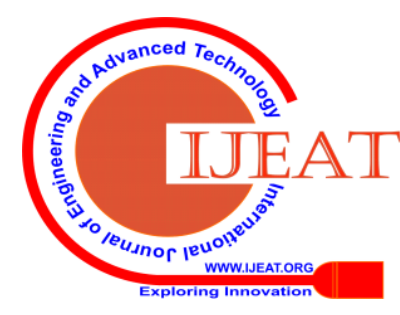




\section{Automatic Detection of Carbon Dioxide Concentration using IoT}

4. S. Bonino, "Carbon Dioxide Detection and Indoor Air Quality Control," 01042016.2 [Online]. Available: https://ohsonline.com/articles/2016/04/01/

carbon-dioxide-detection-and-indoor-air-quality-control.aspx.

5. S. Akhai, P. Thareja and V. Singh, "Assessment of Indoor Environment Health Sustenance in Air Conditioned Class Rooms," J Adv Res Civil Env Eng, pp. 1-9, 2017.

6. M. Cetin, "A Change in the Amount of $\mathrm{CO} 2$ at the Center of the Examination Halls: Case Study of Turkey," Studies on Ethno-Medicine vol. 10, no. 2,

7. H. Sevik, N. Belkayah, Ç. Sakici, E. Ayan, E. Şenöz and H. Karakaş, "Possibilities of Improving Indoor Air Quality in Classrooms through Plants," Journal of Chemical, Biological and Physical Sciences, pp. 2115-2121, 2015.

8. D. A. Coley and A. Beisteiner, "Carbon Dioxide Levels and Ventilation Rates in Schools," International Journal of Ventilation, pp. 45-52, 2002.

9. G. Sfikas, C. Akasiadis and E. Spyrou, "Creating a Smart Room using an IoT approach," 2016.

10. C. Shen, "An investigation of a low-cost CO2 indoor air quality monitor," University of Nottingham, Nottingham, 2014.

11. L. M. Candanedo and V. Feldheim, "2015_Accurate occupancy detection of an office room from light, temperature, humidity, c02 using statistical learning models," Energy and Buildings, pp. 28-39, 2016.

12. L. Zhengzhou Winsen Electronics Technology Co., "Intelligent Infrared CO2 Module (Model: MH-Z19B) User's Manual," 2019. [Online]. Available: https://www.winsen-sensor.com/d/files/ MH-Z19B.pdf.

\section{AUTHORS PROFILE}

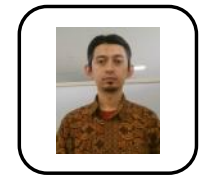

Boby Siswanto, received his Magister degree in Computer Science from Telkom University. Currently he is working as a lecturer at Department of Computer Science, Bina Nusantara University, Bandung Campus. His research interest is Data Mining and Internet of Things.

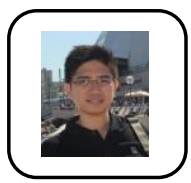

Dr. Johan M. Kerta, received his Magister degree and Doctor of Research in Management Information System degree from Bina Nusantara University. Currently he is working as a lecturer at Department of Computer Science, Bina Nusantara University, Bandung Campus. His research interest is Networking and Management Information System.

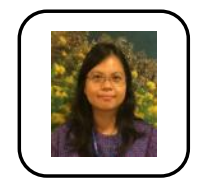

Ranny, received her Magister degree in Computer Science from University of Indonesia. Currently she is working as a lecturer at Department of Computer Science, Bina Nusantara University, Bandung Campus. Her research interest is Algorithm and Artificial Intelligence.

Devwanto D. Nugroho, currently pursuing his Bachelor degree at Department of Computer Science, Bina Nusantara University. His research interest is Programming and Internet of Things.

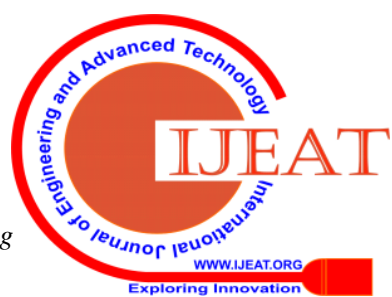

